\title{
A review and selection of simple laboratory methods used for the study of glycosaminoglycan excretion and the diagnosis of the mucopolysaccharidoses
}

\author{
C. A. PENNOCK
}

From the Department of Child Health, University of Bristol

SYNOPSIS The current state of knowledge on the biochemical abnormalities in the mucopolysaccharidoses is reviewed. Methods for the estimation and identification of glycosaminoglycans excreted in the mucopolysaccharidoses are discussed and a selection of simple and reliable methods of value in a small hospital laboratory have been given in detail in an appendix.

The mucopolysaccharidoses are a rare group of inherited disorders of connective tissue metabolism of which the condition most familiar to clinicians is Hurler's syndrome (previously given the unpleasant name 'gargoylism' due to the unusual facial appearance). The clinical features have been reviewed by McKusick and others (McKusick et al, 1965; McKusick, 1969, 1972). These disorders have long been known to be associated with excessive mucopolysaccharide excretion (Dorfman and Lorincz, 1957; Meyer et al, 1958). The term mucopolysaccharide, although still retained in medical literature, does lead to confusion between polysaccharides containing both hexosamines and hexuronic acids and a variety of mucins and other mucosubstances which do not contain hexuronic acids. Jeanloz (1960) introduced the term glycosaminoglycuronans (GAG) for the acidic polysaccharides only, and the current nomenclature and suitable abbreviations for these compounds are given in table I. Knowledge of the detailed structure of these compounds has been reviewed by Muir (1969) and Dorfman and Matalon (1972) and is summarized in table II. The amino sugar residues may be $\mathrm{N}$-acetylated, $\mathrm{N}$-sulphated or O-sulphated at carbon 4 or carbon 6 . In the interests of clarity, the trivial names of the residues will be used throughout the rest of this article, for example, 2-acetamido-2-deoxy- $\alpha$-D-glucopyranose will be referred to as $\mathrm{N}$-acetylglucosamine.

In 1964 Van Hoof and Hers identified the mucopolysaccharidoses as lysosomal storage disorders by electron microscopy, and since that date it has become increasingly apparent that they are due to genetic defects in the synthesis and activity of

Received for publication 11 August 1975

\begin{tabular}{|c|c|c|}
\hline Past Name & Current Name & Abbreviation \\
\hline $\begin{array}{l}\text { Acid mucopolysaccharide } \\
\text { Hyaluronic acid } \\
\text { Chondroitin } \\
\text { Chondroitin sulphate A } \\
\text { Chondroitin sulphate B } \\
\text { Chondroitin sulphate C } \\
\text { Heparin }\end{array}$ & $\begin{array}{l}\text { Glycosaminoglycuronan' } \\
\text { Hyaluronic acid } \\
\text { Chondroitin } \\
\text { Chondroitin-4-sulphate } \\
\text { Dermatan sulphate } \\
\text { Chondroitin-6-sulphate } \\
\text { Heparin }\end{array}$ & $\begin{array}{l}\text { GAG } \\
\text { HA } \\
\text { Ch } \\
\text { C-4-S } \\
\text { DS } \\
\text { C-6-S } \\
\text { Hep }\end{array}$ \\
\hline $\begin{array}{l}\text { Heparitin sulphate } \\
\text { Heparin monosulphate }\end{array}$ & Heparan sulphate & HS \\
\hline $\begin{array}{l}\text { Corneal keratosulphate } \\
\text { Skeletal keratosulphate } \\
\text { Chondroprotein } \\
\text { Protein-polysaccharide } \\
\text { complex }\end{array}$ & $\begin{array}{l}\text { Keratan sulphate I } \\
\text { Keratan sulphate II } \\
\text { Proteoglycan }\end{array}$ & $\begin{array}{l}\text { KS I } \\
\text { KS II }\end{array}$ \\
\hline
\end{tabular}

Table I Current nomenclature based on the work of Jeanloz (1960)

${ }^{1}$ The term glycosaminoglycan is usually preferred in current literature since glycosaminoglycuronans contain hexuronic acids, and this term would not include the keratan sulphates which contain galactose instead of hexuronic acid residues.

enzymes essential for the degradation of connective tissue GAG. Fratantoni et al (1968a) incubated cultured fibroblasts from patients with mucopolysacchridoses, in the presence of ${ }^{35} \mathrm{~S}$-labelled sulphate, and showed increased accumulation and delayed release of label in abnormal cells compared with normal controls and concluded that this indicated defective degradation of synthesized GAG. In the same year they (1968b) also published the exciting finding that when Hurler and Hunter cells were mixed, here was a normal sulphate uptake as a result of the diffusion of 'corrective factors' from one cell type to the other; these factors were found in the supernatant fluid and have since been isolated from 


\begin{tabular}{|c|c|c|c|c|}
\hline$G A G$ & Abbreviation & Amino Sugar & Hexuronic Acid & Sulphate \\
\hline $\begin{array}{l}\text { Hyaluronic acid } \\
\text { Chondroitin } \\
\text { Chondroitin-4-sulphate } \\
\text { Chondroitin-6-sulphate } \\
\text { Dermatan sulphate }\end{array}$ & $\begin{array}{l}\text { HA } \\
\text { Ch } \\
C_{4} S \\
C_{8} S \\
\text { DS }\end{array}$ & $\begin{array}{l}\text { Glu N } \\
\text { Gal N } \\
\text { Gal N } \\
\text { Gal N } \\
\text { Gal N }\end{array}$ & $\begin{array}{l}\text { GUA } \\
\text { GUA } \\
\text { GUA } \\
\text { GUA } \\
\text { GUA } \\
\text { IDA }\end{array}$ & $\begin{array}{l}- \\
\overline{\mathrm{O}}-\mathrm{SO}_{4} \\
\mathrm{O}_{4} \mathrm{SO}_{4} \\
\mathrm{O}-\mathrm{SO}_{4}\end{array}$ \\
\hline Heparan sulphate & HS & Glu N & $\begin{array}{l}\text { GUA } \\
\text { IDA }\end{array}$ & $\begin{array}{l}\mathrm{O}-\mathrm{SO}_{4} \\
\mathrm{~N}-\mathrm{SO}_{4}\end{array}$ \\
\hline Heparin & Hep & Glu N & $\begin{array}{l}\text { GUA } \\
\text { IDA }\end{array}$ & $\mathrm{O}-\mathrm{SO}_{4}$ \\
\hline Keratan sulphate & $\mathbf{K S}$ & Glu N & None $^{1}$ & $\mathrm{O}-\mathrm{SO}_{4}$ \\
\hline
\end{tabular}

Table II Structure of $G A G$

$\begin{array}{cll}\text { Abbreviations: } & \text { Glu N } & \text { glucosamine } \\ \text { Gal N } & \begin{array}{l}\text { galactosamine } \\ \text { GUA }\end{array} & \begin{array}{l}\text { glucuronic acid } \\ \text { iduronic acid }\end{array}\end{array}$

${ }^{1} \mathrm{KS}$ contains galactose instead of hexuronic acid.

The hexosamine residues are $\mathrm{N}$-acetylated except in the case of Hep and HS where some residues are N-sulphated. IDA is the C-5 epimer of GUA.

normal human urine. Their enzymic nature was suggested by Cantz et al $(1970,1972)$ and Bach et al (1972).

Recently, a number of specific enzyme defects have been identified and have led to a slight modification of the earlier classifications (McKusick, 1972). The current state of knowledge on enzyme defects is summarized in table III. The importance of these recent enzyme discoveries is threefold:

1. With suitable assay procedures they should enable an unequivocal diagnosis of the different mucopolysaccharidoses to be made.

2. Enzyme assays on cultured amniotic fluid cells will enable early intrauterine diagnosis to be made.

3. Suitable enzyme-replacement therapy may be possible.

However, at the time of writing, enzyme assays are not widely used for diagnosis because suitable substrates are not readily available (with the exception of p-nitrophenyl- $\alpha$-D-glucosamine for type III B), and substrate preparation and the culture of tissue cells are difficult and time-consuming. Urine analysis for excessive and abnormal GAG excre-음 tion is, therefore, likely to remain important for some time to come as the initial diagnostic test.

An extensive literature has developed in recent years on methods used for detection and evaluation of abnormal GAG excretion. Most have been developed in research laboratories and require $\overrightarrow{0}$ special apparatus and expertise not usually availabee. in clinical chemistry departments. As a result mary laboratories are reluctant to enter this field owing

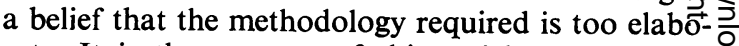
rate. It is the purpose of this article to discuss a number of simple procedures which are reliable and $\stackrel{\otimes}{\varnothing}$ adequate for diagnostic purposes and to recommend $\stackrel{2}{\Rightarrow}$ those which the author has found to be most useful. The latter are described in detail in the appendix.

\section{The Sample}

The diagnosis of mucopolysaccharidoses is most likely to be required in early childhood when $24-$ hour specimens of urine are difficult to collect. The problem of incomplete collections may be overcome

\begin{tabular}{|c|c|c|c|}
\hline Mucopolysaccharidosis & Type & Enzyme Defect & References \\
\hline $\begin{array}{l}\text { Hurler } \\
\text { Scheie }\end{array}$ & $\begin{array}{l}\text { IH } \\
\text { IS (formerly V) }\end{array}$ & $\alpha$ L-iduronidase & Matalon and Dorfman (1972) \\
\hline Hunter & II & L-iduronosulphate sulphatase & Bach et al (1973); Sjöberg et al (1973) \\
\hline Sanfilippo & IIIA & Heparan sulphate sulphamidase & Kresse (1973) \\
\hline Sanfilippo & IIIB & $\alpha \mathrm{N}$ acetylglucosaminidase & O'Brien (1972); von Figura et al (1973) \\
\hline Morquio & IV & $\mathrm{N}$-acetyl hexosamine-4-sulphate sulphatase & Matalon et al (1974) \\
\hline Maroteaux Lamy & VI & Arylsulphatase B & Stumpf et al (1973) \\
\hline$\beta$ glucuronidase ${ }^{2}$ deficiency & VII & $\beta$ glucuronidase & Sly et al (1973); Beaudet et al (1972) \\
\hline
\end{tabular}

Table III Current views on the enzyme defect in the mucopolysaccharidoses

${ }^{1}$ McKusick (1972).

'Only two patients have been described with this disorder. In one, urinary GAG were normal (Sly et al, 1973) and in the other DS excretion was elevated (Beaudet et al, 1972). 
by relating GAG excretion to creatinine excretion, and this may be done on random samples of urine collected from outpatients. Although creatinine excretion varies during a 24-hour period and the GAG/creatinine ratio is increased at night (Di Ferrante and Lipscomb, 1970), the excretion of both substances remains fairly constant during waking hours (say 0900-1800 hours) and the GAG/creatinine ratios in samples obtained during this period are similar to those obtained on complete 24-hour urine collections (Pennock et al, 1973).

Infected samples should not be used, but some preservatives may interfere with the analyses, eg, thymol interferes with some screening tests and toluene lowers the efficiency of precipitation methods (Di Ferrante, 1967). Their use is best avoided if possible, and the author prefers samples to be frozen solid as soon as possible after collection, and kept frozen during transport to the laboratory and while awaiting analysis. However, freezing is not essential, and adequate diagnostic information can be gained from the analysis of samples which have been sent through the post provided the sample is not infected. For postal delivery, the author requests three or more random samples of urine collected at different times; all non-infected samples can be pooled, and this usually gives enough material for a full qualitative analysis if necessary (see below).

Some urine samples may be very concentrated, which may lead to inadequate isolation of GAG and hence error in quantitative analyses (Di Ferrante, 1967). The sample should be diluted with distilled water to lower the specific gravity to below 1.020 before any tests, including estimation of creatinine, are done. Very dilute samples of low specific gravity and creatinine content should be discarded since small errors in the estimation of the latter may give false positive or false negative results.

\section{Screening Tests}

The main objectives in selecting any chemical screening test should be that the test (1) should never give a false negative result, (2) is easy and quick to perform, and (3) gives a minimum number of false positive results which would require further analysis. Although a large number of screening tests have been devised, the majority fail on at least one of these criteria, mainly because they take no account of urine concentration. If an identical volume of urine is used in each case, a concentrated urine from a normal individual may give a false positive result while a dilute urine from a patient with a mucopolysaccharidosis will give a false negative result.

Screening tests fall into two main categories, paper spot tests based on the interaction of urinary GAG with a suitable cationic dye, and precipitation tests based on the interaction of GAG with acidified albumin, quaternary ammonium compounds, or alcian blue.

\section{Spot Tests}

A number of paper spot tests have been described in which a fixed volume of urine is applied to filter paper, dried, and stained with a solution of suitable dye. The dyes used have included toluidine blue (Berry and Spinanger, 1960), alcian blue (Carson and Neill, 1962; Procopsis et al, 1968), and azur A (Berman et al, 1971). None of these tests takes urine concentration or age-related changes in GAG excretion into account. Carter et al (1968) found 31.5\% false negative results using toluidine blue to test 54 urine samples from patients with Hurler's syndrome, and Procopsis et al (1968) found a false negative result using alcian blue. Allowing for the urine concentration by spotting a urine volume containing a fixed amount of creatinine does not climinate false negative results. The method using azur $\mathbf{A}$ (Berman et al, 1971) was based on a study of only 17 samples. This test does not take urine concentration into account, and the recommended procedure seems unlikely to be an improvement on the other screening tests.

In view of the high incidence of false negative results, paper spot tests should not be used as screening tests for the mucopolysaccharidoses.

\section{Precipitation Tests}

The interaction of GAG with acidified bovine albumin to form a flocculent precipitate has also been used as a screening test (Dorfman, 1958; Denny and Dutton, 1962). This test also does not take urine concentration into account, and false negative results have been found in three patients with Hurler's syndrome and three patients with Sanfilippo syndrome using the test in its original form (Pennock et al, 1973). Even when refined by quantitative measurement of the turbidity (Steiness, 1961) false negative results have also been found in $9.2 \%$ of samples from patients with Hurler's syndrome (Carter et al, 1968) and in patients with Sanfilippo syndrome (Lewis et al, 1974).

The observation that GAG will react with quaternary ammonium compounds to give a precipitate (Scott, 1960) has also been used as a screening test. Renuart (1966) added a buffered solution of cetyltrimetryl ammonium bromide (CTAB) to urine and observed a flocculent precipitate after 30 minutes in samples with high GAG content. In the author's experience this test is often difficult to interpret since 
normal urines frequently give a peculiar precipitate and a true flocculent precipitate is so rarely seen that it is difficult to explain to an inexperienced observer what to look for.

A semiquantitative test in which cetylpyridinium chloride (CPC) is added to urine and the turbidity recorded was described by Manley and Hawksworth (1966). They found that timing was critical since aggregation of particles occurred after four minutes. They also found that results changed with age throughout childhood, but again this test does not take urine concentration into account.

Precipitation of GAG with CPC or CTAB is affected by ionic strength and pH (Scott, 1960) as well as by concentration and, if these factors are not taken into account, urine samples may give false positive or false negative results. The effects of ionic strength and $\mathrm{pH}$ can be overcome by buffering the CPC solution, and the use of citrate buffer at $\mathrm{pH}$ 4.8 (Pennock, 1969) also overcomes the critical time dependence of the CPC test as described by Manley and Hawksworth (1966). The inclusion of standards enables a quantitative result to be obtained. It is essential that allowance is made for urine concentration effects by relating the results to the creatinine content of the sample, and that it is appreciated that GAG excretion changes with age throughout childhood so that the correct normal range can be used (Pennock, 1969). The CPC citrate test has the following advantages over other screening tests:

1. The effects of differences in ionic strength and $\mathrm{pH}$ of the sample are overcome.

2. The precipitate is stabilized so that timing of the reaction is less critical.

3. It is quantitative and thus lends itself to quality control.

4. By relating results to creatinine, account is taken of urine concentration.

5. It may be applied to random urine samples.

6. The test has not been known to give false negative results even in patients with Sanfilippo syndrome when other screening tests have failed (Pennock, 1973; B. Turner-personal communication).

7. The incidence of false positive results is acceptable; $5 \%$ in the first year of life and $2.6 \%$ in older children were found in one study of 3000 children (Pennock et al, 1973) and 3.6\% in another study of 1000 children (Valdivieso et al, 1973).

It is for these reasons that the CPC citrate test is given in more detail as the screening method of choice in the appendix.

\section{Quantitative Estimation of Urinary GAG}

Quantitative estimation is based on measurement of hexuronic acid residues which all the GAG contain except keratan sulphate. Separation of GAG from interfering substances has been achieved in a number:of ways. Hexuronic acid may be measured on the dialysed sample directly (Segni et al, 1964 Rosenfeld, 1971) or after a further purification step such as fractionation on ECTEOLA cellulosen columns, which enables sulphated and non-sulphated GAG to be measured separately (Wessler, 1967 Blackham and Raine, 1970), or by precipitation with" CTAB or CPC (Thompson and Castor, 1966; Tellep et $a l, 1962)$ or aminoacridine (Bitter et al, 1970 $\overrightarrow{\vec{t}}$ Dean et al, 1971). CPC and CTAB are poor prew cipitants of GAG in the absence of salts, and it is? preferable to use the method described by $D_{\text {H }}$ Ferrante and Rich (1956) in which these agents are added to untreated urine. CPC is the best of the three. precipitants in the presence of urinary salts (DL Ferrante, 1967) although glycoproteins tend to bee co-precipitated. The latter problem is easily overcome as a higher concentration of precipitant than recommended by Di Ferrante (1967) leaves? glycoproteins in solution (Goldberg and Cotlier 1972; Pennock, 1973). Aminoacridine has not been widely used because, in addition to being less efficiento than CPC, the method is more time consuming. 8 के

Column chromatography of either dialysed CPC precipitated samples has held an import place in research into GAG excretion patterns is time consuming and results in a large number of fractions for further analysis. However, the addition of urine directly to an ECTEOLA cellulose column? and elution of GAG with a single solvent gives, the same results as CPC precipitation (Di Ferrante 1967).

The amount of hexuronic acid containing materialpresent after dialysis varies with the duration of dialysis, the number of changes of distilled water:and pore size of the membrane, and considerable losses of GAG may occur (Rosenfeld, 1971). This applies particularly to samples from patients with Hurler's syndrome in which up to $50 \%$ of the GACo may be dialysable compared with $11 \%$ in samples from normal subjects (Constantopoulos, 1968) similar losses have been found in Scheie's syndrome even when Visking dialysis tubing was heated to reduce the pore size (Pennock, 1973).

However, despite losses, the hexuronic acid con N tent of a dialysed sample is usually, but not always greater than that recovered by CPC precipitation of untreated urine. The CPC precipitable hexuronie acid was found by Rosenfeld (1971) to be $25-55 \%$ of? non-dialysable hexuronic acid in normal adults ando $70 \%$ in children, and a similar range of $11-65 \%$ in adults but a greater range of $71-156 \%$ in children wass found by Pennock et al (1975), ie, in samples from 
some normal children a large portion of CPC precipitable material will be lost on dialysis. This has also been observed in some patients with mucopolysaccharidoses (see above). It is not known whether the high results in some dialysed samples are due to interfering chromogens, as suggested by Manley $e t$ $a l$ (1968), or to the presence of GAG which is not CPC precipitable, as suggested by Rosenfeld (1971).

Rosenfeld (1971) has shown the presence of at least three GAG types and suggested the possibility of a fourth. GAG may be: (1) high molecular weight, non-dialysable but CPC precipitable; (2) low molecular weight, ultrafilterable, and thus lost on dialysis but CPC precipitable; (3) very low molecular weight, ultrafilterable and lost on dialysis, and not CPC precipitable; (4) low molecular weight and attached to proteins which are neither dialysable nor precipitable. Di Ferrante et al (1972) have confirmed that low molecular weight GAG exist which are not CPC precipitable and which will pass through a Visking dialysis membrane even after reduction of pore size with heat treatment. However, the actual concentration of these low molecular weight GAG in patients with mucopolysaccharidoses is the same as in normal children so that the estimation of this fraction is of little diagnostic value, although further research into their nature could be enlightening. It is important to emphasize that precipitation of GAG with CPC from untreated urine gives the same results as isolation by ECTEOLA cellulose chromatography. The former is the simpler of the two methods and is therefore described in the appendix. Because the proportion of CPC precipitable GAG which is lost on dialysis varies among normal individuals and patients with mucopolysaccharidoses one must reiterate the comment made by Di Ferrante (1967), 'One cannot be too emphatic in discouraging dialysis of urine prior to precipitation'.

Once a suitable GAG preparation has been isolated the estimation of hexuronic acid presents little problem and it may be measured by the carbazole-sulphuric acid method (Dische, 1947) or the borate modification of that method (Bitter and Muir, 1962). The latter gives almost equal colour yield for glucuronic and iduronic acid and may be carried out as a single step reaction in the modified manner described in the appendix.

Whiteman $(1973 \mathrm{a}, \mathrm{b})$ has described a quantitative test in which GAG are precipitated with alcian blue and the dye is ultimately eluted from the precipitate and measured colorimetrically. This test may offer advantages over CPC precipitation in that the colour yield for equal amounts of different GAG is almost identical and keratan sulphate is precipitated. Results by this method tend to be slightly higher than those obtained by measuring CPC precipitable hexuronic acid, and this may be due to other unknown reactants but there is a reasonable correlation between the two methods (Whiteman, 1973b). Full details of this test as an alternative to the CPC citrate test are not included in the appendix since it has been used in only a few laboratories and its true value has not yet been fully assessed. The precipitate is often very finely dispersed and often difficult to harvest without centrifugation at least at $2000 \mathrm{RCF}$ for 15 minutes, facilities for which may not be available in many small clinical laboratories. It may prove to be of special value in the study of Morquio's disease if it proves more reliable than CPC for the isolation of keratan sulphate (vide infra).

\section{Identification of Type of GAG excreted}

The major GAG excreted by normal individuals is chondroitin-6-sulphate (Di Ferrante, 1969) whereas heparan sulphate, dermatan sulphate, and keratan sulphate are excreted in excess in patients with mucopolysaccharidoses (see interpretation of GAG excretion pattern below and table IV).

\begin{tabular}{|c|c|}
\hline Patient & Major GAG Excreted \\
\hline Normal & Chondroitin-6-sulphate \\
\hline $\begin{array}{l}\text { Type IH } \\
\text { Type IS }\end{array}$ & $\begin{array}{l}\text { Dermatan sulphate and heparan sulphate in } \\
\text { ratio } 3: 1\end{array}$ \\
\hline Type II & $\begin{array}{l}\text { Dermatan sulphate } \\
\text { Heparan sulphate }\end{array}$ \\
\hline Type III & $\begin{array}{l}\text { Heparan sulphate with or without dermatan } \\
\text { sulphate }\end{array}$ \\
\hline Type IV & $\begin{array}{l}\text { Keratan sulphate } \\
\text { Chondroitin-6-sulphate }\end{array}$ \\
\hline Type VI & Dermatan sulphate \\
\hline
\end{tabular}

Table IV Glycosaminoglycan excretion patterns

${ }^{1}$ Pattern may be equal amounts of both GAG or, more often, difficult to distinguish from type I (see text).

Identification of GAG excretion pattern requires simple methods for separating and assessing the relative proportions of heparan, dermatan, and keratan sulphates. Most investigations have used column chromatography but separations are often imperfect (Kaplan, 1969). Full identification requires hydrolysis of the appropriate fractions and structural identification by defining the principal hexosamines (see table II) by further column chromatography which is not only time-consuming but often affords inadequate separation. These methods are quite unsuited to the small hospital laboratory.

Electrophoretic separation may be done in barbitone buffer (Manley and Hawksworth, 1966). Although this method does not separate dermatan 
sulphate (DS) from the chondroitin sulphates (CS) nor heparan sulphate (HS) from keratan sulphate, it is a useful method since galactosamine containing GAG and glucosamine containing GAG migrate as two separate bands. Other separations have been described which are based on GAG structure and include electrophoresis in barium acetate (Wessler, 1968) in which keratan sulphate separates poorly from chondroitin sulphates, and electrophoresis in cupric acetate (Hata and Nagai, 1972) and zinc sulphate (Hardingham and Phelps, 1970), both of which fail to separate heparan and keratan sulphates, and the poorly defined separations of other GAG are more difficult to interpret than those achieved in barbitone or barium acetate (Pennock, 1973). Barium acetate gives good separation of DS and HS (Lewis et al, 1974), and this method has been selected and described in the appendix because of its speed and simplicity.

Thin layer chromatography of GAG has been used by Wusteman et al (1966) who found difficulty in separating dermatan sulphate, and by Teller and Ziemann (1969) who were unable to separate keratan sulphate from other GAG. The best method described so far is that based on the relative solubility of different GAG, as their calcium salts, in alcohol using a sequence of solvents which affords a very rapid and efficient separation of all GAG (Lippiello and Mankin, 1971; Humbel and Chamoles, 1972). The method is included in the appendix with comments on intepretation of patterns of GAG excretion. This is the only method which clearly separates keratan sulphate from other GAG and is thus invaluable in the diagnosis of Morquio's disease.

In summary, the simple tests required include:

1. A reliable screening test for which the CPC citrate test is recommended.

2. Isolation of GAG and estimation as hexuronic acid.

3. Isolation of GAG and identification of excretion pattern by thin layer chromatography and/or electrophoresis.

In most urines, these methods enable a diagnosis to be made but rarely equivocal results may be obtained, and in these cases a more elaborate procedure is necessary such as measuring the proportion of hyaluronidase resistant GAG (Pennock et al, 1973), estimation and identification of hexosamine content by gas liquid chromatography (Murphy et al, 1974), specific estimation of dermatan sulphate (Di Ferrante et al, 1971), estimation of amino sulphate as a measure of heparan sulphate (Lagunoff et al, 1967) or measurement of keratan sulphate as galactose (Robertson and Harvey, 1972). All of these methods are rarely required and are not included in the appendix.
Interpretation of Results and Diagnostic Difficulties

False positive CPC citrate screening tests may be found in some patients on certain drugs such aळ् barbiturates, phenytoin, and penicillins but the mechanism is not understood (Pennock et al, 1970) $\frac{5}{\circ}$ Patients with renal disease and mucoproteinuria wi also give false positive results, since mucoprotein $\overline{8}$ precipitate with CPC, but CPC precipitable hexuð్ ronic acid is usually within normal limits.

Any patient with excessive connective tissue $\vec{\oplus}$ destruction may give a positive CPC citrate screening test and an increased excretion of CPC precipitableg hexuronic acid. Notable examples include ricketक्ष (Valdivieso et al, 1973), malabsorption syndromes with gross osteomalacia, malignant disorders witke extensive secondary deposits (including leukaemia) and patients with disseminated lupus erythematosus (Di Ferrante et al, 1957); some patients with rheumae toid arthritis (Di Ferrante, 1957; Thompson and Castor, 1966) and some with Marfan's syndromen (Berenson and Dalferes, 1965; Bitter et al, 1970) as well as a few other rare disorders (Brimacombe and Stacey, 1964). Qualitative examination of excrete GAG shows that chondroitin sulphates predominate and hence the excretion pattern is similar to norrgaf excretion and easily differentiated from the patern in the mucopolysaccharidoses.

Patients with one of the mucopolysaccharido excrete excessive amounts of heparan, dermatan of keratan sulphates, and the excretion patterns are shown in table IV. The excretion pattern in Hurler's Scheie's, and Maroteaux-Lamy syndromes is cono sistent and easy to interpret. In a detailed study op excretion patterns, Kaplan (1969) found roughl 㞔 equal amounts of heparan sulphate in patients with. Hunter's syndrome. Others have failed to confirno this, finding that the pattern in Hunter's syndrome more frequently resembles the pattern in Hurler' syndrome (Maroteaux, 1970; Pennock, 1973). There? fore, these two conditions cannot always be dis tinguished by the simple methods described. This does not detract from the value of the simple methods since distinction is also difficult to make using more sophisticated techniques, an furthermore the problem is not usually great sincos distinction between the two syndromes may be madew on clinical grounds. Similar comments apply to Scheie's syndrome (MPS Type IS) where the enzyme defect and excretion pattern are identical with those of Hurler's syndrome (Wiesmann and Neufeld, 1970 f but the clinical features are distinctly differen (McKusick, 1972)

In Sanfilippo syndrome, in which there are twक्ष different enzyme defects, there appear to be tw patterns of heparan sulphate excretion which cannos 
be distinguished by electrophoresis (Lewis et al, 1974). However, by thin layer chromatography one type shows a heparan sulphate fraction which migrates in the same position as heparan sulphate from normal urine while the other type shows a heparan sulphate fraction which behaves as if it were chondroitin-4-sulphate. However, the pattern is still distinct from normal and gives no problem in interpretation if electrophoresis in barium acetate is also done when any doubt exists.

The diagnosis of Morquio's disease, although it is clearly a mucopolysaccharidosis with abnormal keratan sulphate metabolism (Robins et al, 1963), should be regarded as a separate problem. This is mainly because keratan sulphate excretion may sometimes be normal, especially in adult life (Maroteaux and Lamy, 1967; Linker et al, 1970; Jenkins et al, 1973). When keratan sulphate excretion is increased the CPC citrate screening test is usually positive and usually there is also an increase in CPC precipitable hexuronic acid since there is a parallel increase in chondroitin sulphate excretion (Pennock, 1973). Although it has been disputed that keratan sulphate is precipitated by CPC, it is now clear that although precipitation is difficult from aqueous solutions it is readily achieved in urine (Di Ferrante, 1967). Indeed the first demonstration of increased keratan sulphate excretion in Morquio's disease by Pedrini et al (1962) was achieved using quaternary ammonium precipitants. Furthermore, it seems likely that most of the keratan sulphate is actually excreted as a complex with chondroitin sulphate similar to the form in which it exists in cartilage although probably of reduced molecular size. Since it is only soluble in excess CPC when it is totally released from its hybrid chondroitin sulphate complex (Goldberg, 1973; Kaplan et al, 1968), most urinary keratan sulphate would precipitate with the chondroitin sulphate fraction. Recently the excretion of keratan sulphate throughout childhood has been studied by Robertson and Harvey (1972), using ion-exchange chromatography followed by GAG precipitation and estimation of keratan sulphate as galactose. This is a potentially useful method for the study of Morquio's disease and other spondyloepiphyseal dysplasias. This disease clearly requires further study, and its separation from the other mucopolysaccharidoses in this sense appears justified.

One final problem is worthy of mention. It is often difficult to distinguish high abnormal GAG excretion from normal results in the neonatal period since GAG excretion in relation to creatinine is high at this time of life even in normal individuals (Pennock et al, 1971). A request for examination of urinary GAG in the first year of life should, therefore, be $2 *$ completed by qualitative examination of the excretion pattern since the latter is usually abnormal from birth in the mucopolysaccharidoses even when total GAG excretion as hexuronic acid is within normal limits, and well before radiological changes are demonstrable (Pennock, 1973).

In conclusion, the methods outlined in the appendix are adequate for the diagnosis of the various mucopolysaccharidoses provided note is taken of the difficulties which may be encountered and which have been discussed in the preceding paragraphs. The methods are simple and require the minimum of apparatus and technical skill and should, therefore, be easily performed in any hospital or laboratory. They will remain of value in the investigation of the mucopolysaccharidoses until such time as suitable enzyme substrates are made available commercially. More specialized or new methods are required for the study of keratan sulphate excretion and the identification of patients with Morquio's disease.

I am indebted to Dr G. Walters for helpful advice during the preparation of this review.

\section{APPENDIX}

Details of methods suitable for a simple study of excess glycosaminoglycan (GAG) excretion for the diagnosis of mucopolysaccharidoses

\section{A. COLLECTION AND PREPARATION OF THE SAMPLE}

Early morning specimens should not be used for screening tests, and infected samples collected at any time are unsuitable for analysis. Either single specimens passed between 0900 and 1800 hours or complete 24-hour specimens should be collected without preservative and stored frozen until analysed. (Freezing is not absolutely essential provided the sample does not become secondarily infected.)

The specific gravity of the sample should be measured and adjusted to less than 1.020 with distilled water if necessary. The sample should be centrifuged and the supernatant used for the estimation of creatinine and for the following tests.

\section{B. SCREENING TEST}

(CPC-citrate turbidity: Pennock, 1969)

\section{Principle}

Under controlled conditions of $\mathrm{pH}$ and electrolyte concentration cetylpyridinium chloride (CPC) reacts with GAGs to form an insoluble precipitate. In the presence of a citrate buffer at $\mathrm{pH} 4.8$ this precipitate 
is sufficiently stabilized and dispersed to measure the absorbance at $680 \mathrm{~nm}$ in a spectrophotometer of filter colorimeter or its turbidity may be measured using a nephelometer.

\section{Reagents}

1. Citrate buffer pH $4.8(0 \cdot 1 \mathrm{M})$. Dissolve $9.68 \mathrm{~g}$ of citric acid (AR) and $15.88 \mathrm{~g}$ of trisodium citrate (AR) in 1 litre of deionized water. Adjust the $\mathrm{pH}$ to 4.8 using a pH meter (little adjustment is usually required as this $\mathrm{pH}$ is close to the $\mathrm{pK}_{2}$ of citric acid).

2. CPC reagent. Dissolve $1 \mathrm{~g}$ of cetylpyridinium chloride in 1 litre of the above buffer. Store at room temperature - shelf life at least one year.

3. Standards. Prepare standard aqueous solutions of chondroitin sulphate (CS) (Calbiochem Ltd) to contain 50 and $100 \mathrm{mg}$ per litre. Store at $4^{\circ} \mathrm{C}$.

\section{Method}

1. Centrifuge the sample and use the supernatant for the test. Allow standards and samples to reach room temperature $\left(20-25^{\circ}\right)$ before testing. (This is extremely important as CPC comes out of solution at low temperature and will do so if added to a cold sample, thus giving a falsely high turbidity.)

2. Mix $1 \mathrm{ml}$ of sample with $1 \mathrm{ml}$ of citrate buffer as a blank.

3. Mix $1 \mathrm{ml}$ of sample with $1 \mathrm{ml}$ of CPC reagent for the test.

4. Mix $1 \mathrm{ml}$ of standard with $1 \mathrm{ml}$ of CPC reagent. 5. Allow to stand at room temperature for at least 30 minutes, remix, and read absorbance of blanks, tests, and standards at $680 \mathrm{~nm}$. (Lower wave lengths, but not less than $450 \mathrm{~nm}$, or filter instruments may be used.) Absorbance (OD) is linear up to a concentration of $100 \mathrm{mg} / \mathrm{l}$.

\section{Calculation and Normal Range \\ OD Test - OD Blank \\ OD Standard $x$ \\ $\frac{\text { Concentration of standard }(\mathrm{mg} / \mathrm{l})}{10}=$}

CPC units per litre

One CPC unit is equivalent to the absorbance given by a solution containing $10 \mathrm{mg} C S$ per litre. The results are not expressed directly in milligrams since different GAGs give slightly different turbidity readings at the same solution concentrations. The results are finally expressed as CPC units per gram of creatinine or per mole of creatinine. The normal range at different ages throughout childhood is given in table I. The uppper limit in the first year of life is an arbitrary one chosen to ensure detection of abnormal samples but which gives a slightly

\begin{tabular}{|c|c|c|}
\hline Age & $\begin{array}{l}\text { CPC units/g } \\
\text { creatinine }\end{array}$ & $\begin{array}{l}\text { CPC units/mMole } \\
\text { creatinine }\end{array}$ \\
\hline $0-6$ months & $300^{1}$ & $34^{1}$ \\
\hline 6 months- 1 year & 280 & 32 \\
\hline $1-2$ years & 262 & 30 \\
\hline $2-3$ years & 244 & 28 \\
\hline $3-4$ years & 228 & 26 \\
\hline 4-5 years & 213 & 24 \\
\hline $5-6$ years & 198 & 22 \\
\hline 6-7 years & 185 & 21 \\
\hline $7-8$ years & 173 & 20 \\
\hline $8-9$ years & 161 & 18 \\
\hline $9-10$ years & 150 & 17 \\
\hline $10-11$ years & 140 & 16 \\
\hline $11-12$ years & 131 & 15 \\
\hline $12-13$ years & 122 & 14 \\
\hline 13-14 years & 114 & 13 \\
\hline $14-18$ years & 100 & 9 \\
\hline Adults & 50 & 5 \\
\hline
\end{tabular}

Table I Upper limit of normal range for CPC citrate screening test (figures given to nearest whole number)

${ }^{1}$ Results higher than this may be found in normal infants in the first 2 weeks of life.

higher percentage of false positive results at this age than is usually found later in life (see text).

C. QUANTITATIVE ESTIMATION OF GAG BY MEASUREMENT OF HEXURONIC ACID CONTENT

Principle

All the glycosaminoglycans, except keratan sulphate, $\stackrel{\mathbb{D}}{\stackrel{\circ}{\circ}}$ contain hexuronic acids as part of the molecule. $\vec{F}$ This will react with carbazole in the presence of $\frac{3}{3}$ concentrated sulphuric acid to give a magentacoloured product. The GAGs must first be isolatedo from other hexuronic acid-containing metabolites, and this is simply achieved by using CPC as pre-? cipitant.

\section{Reagents}

The following reagents are used for isolation of GAG (Di Ferrante, 1967) and estimation of hexuronic오 acid (Bitter and Muir, 1962).

1. CPC reagent. Dissolve $100 \mathrm{~g}$ of cetylpyridinium chloride in 1 litre of deionized water. Store at room temperature. The CPC is only poorly soluble and solution can be achieved by gentle agitation in a warm water bath at approximately $40^{\circ} \mathrm{C}$. Excessive heating $\omega$ should not be used since the CPC will be degraded 2. Potassium acetate in ethanol. Dissolve $10 \mathrm{~g}$ ofo potassium acetate in 1 litre of absolute ethanol.

3. Borate-sulphuric acid reagent. Dissolve $9.5 \mathrm{~g}$ of ${ }^{?}$ sodium tetraborate decahydrate (AR) in 1 litre? concentrated sulphuric acid (AR). Store at $4^{\circ} \mathrm{C}-\stackrel{\vec{D}}{\mathbb{C}}$ shelf life in excess of one year.

4. Carbazole reagent. Dissolve $1.25 \mathrm{~g}$ carbazole in $\overrightarrow{\mathbb{D}}$ 
1 litre of $95 \%$ ethanol (AR). (In practice it is best to prepare a smaller volume and store in a dark bottle as the shelf life does not exceed three months.)

5. Hexuronic acid standards. Dissolve glucuronolactone (previously dried in a vacuum desiccator over phosphorus pentoxide for three days) in a solution containing $30 \mathrm{~g}$ of benzoic acid per litre, to give final concentrations of $100,80,60,40,20 \mathrm{mg} / \mathrm{l}$ or prepare a stock solution containing $1.7613 \mathrm{~g} / \mathrm{l}$ $(10 \mathrm{mM})$ and dilute to give standards containing 500 , $400,300,200,100 \mu \mathrm{M} /$ litre of benzoic acid solution.

\section{Method}

(a) Isolation of GAGs

1. Place $5 \mathrm{ml}$ of filtered sample prepared as described in section $A$ in a $15 \times 90 \mathrm{~mm}$ disposable polystyrene tube (Metal Box Co Ltd) and add $0.2 \mathrm{ml}$ of CPC reagent. Mix well and stand overnight at $4^{\circ} \mathrm{C}$. 2. Centrifuge for 15 minutes in a standard bench centrifuge at $3000 \mathrm{rev} / \mathrm{min}$. Carefully remove supernatant with a Pasteur pipette and discard.

3. Add $5 \mathrm{ml}$ of potassium acetate in ethanol to the precipitate, mix well, and stand overnight at $4^{\circ} \mathrm{C}$. Centrifuge again at $3000 \mathrm{rev} / \mathrm{min}$ for 15 minutes, discard supernatant, and invert the tube on filter paper to drain. (The precipitate should be sufficiently well packed not to become dislodged.)

4. Add $1 \mathrm{ml}$ of deionized water and $\mathrm{mix}$ well to dissolve the precipitate. (If the screening test result was very high add $5 \mathrm{ml}$ of water.) If the precipitate does not dissolve immediately, leave at room temperature for 1 hour with frequent mixing. Centrifuge, if necessary, to remove insoluble material and use supernatant for hexuronic acid assay.

(b) Hexuronic Acid Assay

1. Place $0.2 \mathrm{ml}$ of the final sample in a $15 \times 125 \mathrm{~mm}$ Pyrex tube.

2. Add $0.2 \mathrm{ml}$ of carbazole reagent.

3. Add $2.0 \mathrm{ml}$ of cold borate-sulphuric acid reagent.

4. Stopper the tubes. Mix well (at least 15 seconds on a vortex mixer). The mixing is extremely important. If narrower bore tubes are used, adequate mixing is difficult owing to the viscosity of the sulphuric acid. 5. Set up water (blank) and standards in the same way.

6. Transfer to a vigourously boiling water bath for 7 minutes (the time is not critical between 7 and 10 minutes). Deionized water should be used in the water bath since chlorine in tap water may affect the reaction and give a green product.

7. Remove from water bath, cool to room temperature, and read the absorbance in a $1 \mathrm{~cm}$ light path cuvette at $530 \mathrm{~nm}$. (The colour is stable for several hours if stored in the dark.)

8. Calculate the concentration per litre from the

\begin{tabular}{lll}
\hline Age & \multicolumn{2}{l}{ Hexuronic Acid } \\
\cline { 2 - 3 } & $m g / g$ creatinine & $\begin{array}{l}\text { mMoles/mole } \\
\text { creatinine }\end{array}$ \\
\hline 0-3 weeks & Rising from 40-85 & Rising from 23.3-49.5 \\
3 weeks-6 months & Falling to 38.4 & Falling to 22.4 \\
6 months-1 year & $38 \cdot 4$ & $22 \cdot 4$ \\
1-2 years & $35 \cdot 6$ & $20 \cdot 7$ \\
2-3 years & $27 \cdot 2$ & $16 \cdot 0$ \\
3-4 years & $26 \cdot 9$ & $15 \cdot 7$ \\
4-5 years & $25 \cdot 7$ & $15 \cdot 0$ \\
5-6 years & $20 \cdot 7$ & $12 \cdot 0$ \\
6-7 years & $16 \cdot 5$ & $9 \cdot 6$ \\
7-9 years & $13 \cdot 6$ & $7 \cdot 9$ \\
9-10 years & $11 \cdot 3$ & $6 \cdot 6$ \\
10-11 years & $10 \cdot 3$ & $6 \cdot 0$ \\
11-19 years & $9 \cdot 1$ & $5 \cdot 3$ \\
Adults & $6 \cdot 2$ & $3 \cdot 6$ \\
\hline
\end{tabular}

Table II Upper limit of normal range for $G A G$ hexuronic acid in relation to creatinine at different ages (Pennock et al, 1971 and 1972)

standard curve. Note that this value is five times the original urine concentration if $1 \mathrm{ml}$ of water was added at step 4 of the isolation procedure and is equal to the original urine concentration if $5 \mathrm{ml}$ was added. Results are expressed in relation to the creatinine content of the urine sample, and the normal range is given in table II.

\section{IDENTIFICATION OF GAG EXCRETION PATTERN}

\section{Isolation of $G A G$}

Isolation of GAG is achieved by the method described in section C using $100 \mathrm{ml}$ of urine (SG adjusted to less than 1.020) and increasing the CPC reagent volume to $4 \mathrm{ml}$. The larger volumes involved may present difficulties in centrifugation if only a standard bench centrifuge is available. In the author's laboratory the precipitation is usually done in $25 \mathrm{ml}$ aliquots of urine, adding $1 \mathrm{ml}$ of CPC reagent, in universal glass specimen collection containers. After CPC precipitation overnight at $4^{\circ} \mathrm{C}$ the harvested precipitate is mixed with $2-3 \mathrm{ml}$ of potassium acetate in ethanol, and the precipitates are pooled from all bottles and transferred to a single bottle. A further aliquot of alcohol reagent is added to wash final traces from each bottle, and the washings are added to the final bottle. The final volume is made up to approximately $25 \mathrm{ml}$ with more alcohol reagent and left overnight at $4^{\circ} \mathrm{C}$. The precipitate is harvested by centrifugation and washed once with a few millilitres of diethyl ether, dried, and taken up in deionized water. Sufficient water should be added to give a final GAG concentration in the region of $2.5-5 \mathrm{mM}$ per litre in terms of hexuronic acid. This volume is calculated from the known concentration of CPC precipitable hexuronic acid 
in the original urine. The final solution is centrifuged and the supernatant is used for electrophoresis and chromatography.

\section{Electrophoresis (based on Wessler (1968))}

Electrophoresis is done on any type of cellulose acetate membrane. (In the author's laboratory $5 \times$ $18 \mathrm{~cm}$ strips of Oxoid cellulose acetate are used. Other workers prefer Sepraphore III which gives slightly better separation. The running times given below apply to Oxoid cellulose acetate and may need to be shortened for other types of cellulose membrane.) The membrane is soaked in the electrolyte solution for at least 20 minutes before use. It should be floated on the surface to allow electrolyte solution to soak up through the membrane before full submersion, since immediate submersion will result in uneven wetting of membrane and ultimate poor separations. The membrane is then blotted between Whatman No. 1 filter paper to remove excess electrolyte and then placed across a Shandon electrophoresis tank with a $10 \mathrm{~cm}$ bridge gap. Conducting wicks are made of Whatman No. 1 filter paper. Current should be applied to the membrane for about 10 minutes, before application and separation of the sample, in order to obtain an even distribution of electrolyte and water through the membrane.

The sample is applied with a $20 \mu$ l pipette, using a ruler as a guiding edge, and approximately $10 \mu \mathrm{l}$ is applied as an even streak approximately $2 \mathrm{~cm}$ in length and $3 \mathrm{~cm}$ from the anode. A marker solution containing $2 \mathrm{mg}$ of chondroitin sulphate and $2 \mathrm{mg}$ of heparin per $\mathrm{ml}$ should be applied to a separate strip.

Electrophoresis is done in $0.1 \mathrm{M}$ barium acetate at $2 \mathrm{~mA} / \mathrm{cm}$ constant current for three hours. The strips are stained as described below.

\section{Staining of Separated $G A G$}

Electrophoretic strips are stained for 30 minutes in $1 \%$ alcian blue in $2.5 \%$ acetic acid. The strips are floated onto the stain to allow complete uptake of dye before full submersion. The strips are then washed in running tap water until a clear white background is achieved. They may be inspected visually or dried between Whatman No. 1 filter paper overnight, cleared in Whitmor transparency oil (Shandon Southern Ltd) and scanning using a scanning densitometer.

Electrophoresis in barium acetate gives separation with the following order of decreasing mobilityCS, KS, DS, HS, Hep. KS separates poorly from CS, HS separates poorly from DS, and HA migrates with DS. Some samples of heparin contain an HS fraction but neither Hep nor HA are prominent fractions in normal urine. This electrophoretic method is not perfect but, taken in conjunction witp thin layer chromatography, sufficient data are obtained for reliable interpretation.

3. Thin Layer Chromatography (TLC) (Humbel and Chamoles, 1972)

This method is based on the differences in solubility of the calcium salts of GAG in different concentra $\mathbb{2}$ tions of alcohol. The thin layer plate is chromato graphed through six separate solutions of decreas- ing alcohol concentration. Cellulose plates $0.1 \mathrm{~mm}$ thick, $20 \times 20 \mathrm{~cm}$ (Polygram CEL 300 Camblab $\overrightarrow{\vec{\omega}}$ Cambridge), are marked with a soft pencil at $2 \mathrm{cme}$ distances from the bottom of the plate. Approxi mately $10 \mu \mathrm{l}$ of GAG solution is applied on the first line in a thin streak, $1-2 \mathrm{~cm}$ in width, and dried The plate is then placed in the first solvent and this is allowed to ascend to the second line. The plate is then removed, excess solvent being quickly re-을 moved by touching the bottom of the plate onWhatman No. 1 filter paper, and transferred to the ${ }_{\infty}^{T}$ second tank containing solvent 2 , which is then은 allowed to ascend to the third line. This sequence is repeated until all six solvents have been used. If insufficient tanks are available, two may be used, and $\vec{\varphi}$ the tank not in use at any one time can be cleanedo out and the next solvent added. Fifty millilitres solvent is adequate for each tank and the solve concentrations are as follows:

1. $25 \mathrm{~g}$ calcium acetate per litre of $70 \% \mathrm{v} / \mathrm{v}$ ethanol in $0.5 \mathrm{M}$ acetic acid

2. $50 \mathrm{~g}$ calcium acetate per litre of $50 \% \mathrm{v} / \mathrm{v}$ ethanol in $0.5 \mathrm{M}$ acetic acid

3. $50 \mathrm{~g}$ calcium acetate per litre of $40 \% \mathrm{v} / \mathrm{v}$ ethanol in $0.5 \mathrm{M}$ acetic acid

4. $50 \mathrm{~g}$ calcium acetate per litre of $30 \% \mathrm{v} / \mathrm{v}$ ethanol in $0.5 \mathrm{M}$ acetic acid

5. $50 \mathrm{~g}$ calcium acetate per litre of $20 \% \mathrm{v} / \mathrm{v}$ ethanol in $0.5 \mathrm{M}$ acetic acid

6. $50 \mathrm{~g}$ calcium acetate per litre of

$10 \% \mathrm{v} / \mathrm{v}$ ethanol in $0.5 \mathrm{M}$ acetic acid

The first solution has a slightly higher concentra- 9 tion of alcohol than that used by Humbel and $D$ Chamoles (1972) and affords a better separation of KS. The solvents must be prepared fresh for each separation.

After the chromatography is complete the plate is 0 dried and stained for 10 minutes in $1 \%$ alcian blue $8 \mathrm{GX}$ in $70 \%$ ethanol-acetic acid mixture $(95 / 5 / \mathrm{v} / \mathrm{v})$. 우 The plate is washed with $10 \%$ acetic acid to remove as much excess dye as possible.

If the individual solvent fronts are numbered 1 to $6 \stackrel{\oplus}{?}$ from the origin, the migration position of different $\square$ GAG in relation to these fronts is as follows:

DS(1-2), HS(2-3), $C_{4} S(4), C_{6} S(4-5)$, and $\mathrm{KS}(5-6)$.

Interpretation is easier than with electrophoresis. 
Normal urines contain predominantly chondroitin6-sulphate with trace amounts of other GAG. DS and HS are well separated from each other and from other GAGs, and their relative proportions may be used to establish a diagnosis in line with the results shown in table IV of the main text. The method is excellent for detection of $\mathrm{KS}$ in patients with Morquio's disease. HS in some patients with Sanfilippo syndrome migrates a little further than HS in patients with Hurler's syndrome. This is clearly the best simple method for qualitative GAG identification described up to the present time.

\section{References}

Bach, G., Eisenberg, F., Jr., Cantz, M., and Neufeld, E. (1973). The defect in the Hunter syndrome: deficiency of sulfoiduronate sulfatase. Proc. nat. Acad. Sci. (Wash.), 70, 2134-2138.

Bach, G., Friedman, R., Weissmann, B., and Neufeld, E. F. (1972). The defect in the Hurler and Scheie syndromes: deficiency of a-L-iduronidase. Proc. nat. Acad. Sci. (Wash.), 69, 2048-2051.

Beaudet, A. L., Di Ferrante, N., Nichol, S. B., and Ferry, G. D. (1972). $\beta$ Glucuronidase deficiency: altered enzyme substrate recognition. (Abstr.) Amer. J. hum. Genet., 24, 25a.

Berenson, G. S. and Dalferes, E. R., Jr. (1965). Urinary excretion of mucopolysaccharides in normal individuals and in the Marfan syndrome. Biochem. biophys. Acta, 101, 183-192.

Berman, E. R., Vered, J., and Bach, G. (1971). A reliable spot test for mucopolysaccharidoses. Clin. Chem., 17, 886-890.

Berry, H. K. and Spinanger, J. (1960). A paper spot test useful in study of Hurler's syndrome. J. Lab. clin. Med., 55, 136-138.

Bitter, T. and Muir, H. M. (1962). A modified uronic acid carbazole reaction. Ann. Biochem., 4, 330-334.

Bitter, T., Siegenthaler, P., Depreux, T., and Martin, E. (1970). Excretion in the urine of aminoacridine precipitable polyuronides (acid mucopolysaccharides) in patients with rheumatoid arthritis. Ann. rheum. Dis., 29, 427-433.

Blackham, G. A. and Raine, D. N. (1970). The biochemistry of the mucopolysaccharidoses. Ann.clin. Biochem., 6,49-54.

Brimacombe, J. S. and Stacey, M. (1964). Mucopolysaccharides in disease. Advanc. clin. Chem., 7, 199-234.

Cantz, M., Chrambach, A., Bach, A., and Neufeld, E. F. (1972). The Hunter corrective factor: purification and preliminary characterization. J. biol. Chem., 247, 5456-5462.

Cantz, M., Chrambach, A., and Neufeld, E. F. (1970). Characterization of the factor deficient in the Hunter syndrome by polyacrylamide gel electrophoresis. Biochem. biophys. Res. Commun., 39, 936-942.

Carson, N. A. J. and Neill, D. W. (1962). Metabolic abnormalities detected in a survey of mentally backward individuals in Northern Ireland. Arch. Dis. Childh., 37, 505-513.

Carter, C. H., Wan, A. T., and Carpenter, D. G. (1968). Commonly used tests in the detection of Hurler's syndrome. J. Pediat., 73, 217-221.

Constantopoulos, G. (1968). Hunter-Hurler syndrome: gel filtration and dialysis of urinary acid mucopolysaccharides. Nature (Lond.), 220, 583-584.

Dean, M. F., Muir, H., and Ewins, R. J. F. (1971). Hurler's, Hunter's and Morquio's syndromes. A biochemical study in the light of current views of the underlying defects. Biochem. J., 123, 883-894.

Denny, W. and Dutton, G. (1962). Simple urine test for gargoylism. Brit. med. J., 1, 1555.

Di Ferrante, N. (1957). Urinary excretion of acid mucopolysaccharides by patients with rheumatoid arthritis. Fed. Proc., 16, 172-173.

Di Ferrante, N. (1967). The measurement of urinary mucopolysaccharides. Analyt. Biochem., 21, 98-106.

Di Ferrante, N. (1969). Acid mucopolysaccharides of normal human urine. J. Lab. clin. Med., 61, 633-641.

Di Ferrante, N., Donnelly, P. V., and Berglund, R. K. (1971). Colorimetric measurement of dermatan sulphate. Biochem. J., 124, 549-553.

Di Ferrante, N. and Lipscomb, H. S. (1970). Urinary glycosaminoglycans versus creatinine excretion: a used and abused parameter. Clin. chim. Acta, 30, 69-72.

Di Ferrante, N., Neri, G., Neri, M. E., and Hogsett, W. E. III (1972). Measurement of urinary glycosaminoglycans with quaternary ammonium salts: an extension of the method. Connect. Tissue Res., 1, 93-101.

Di Ferrante, N. and Rich, C. (1956). The mucopolysaccharide of normal human urine. Clin. chim. Acta, 1, 519-524.

Di Ferrante, N., Robbins, W. C., and Rich, C. (1957). Urinary excretion of acid mucopolysaccharides by patients with lupus erythematosus. J. Lab. clin. Med., 50, 897-900.

Dische, Z. (1947). A new specific color reaction of hexuronic acids. J. biol. Chem., 167, 189-198.

Dorfman, A. (1958). Studies on the biochemistry of connective tissue. Pediatrics, 22, 576-589.

Dorfman, A. and Lorincz, A. E. (1957). Occurrence of urinary acid mucopolysaccharides in the Hurler syndrome. Proc. Nat. Acad. Sci., 43, 443-447.

Dorfman, A. and Matalon, R. (1972). The Mucopolysaccharidoses in the Metabolic Basis of Inherited Disease, 3rd ed., edited by J. B. Stanbury, J. B. Wyngaarden, and D. S. Fredrickson, Chap. 49, pp. 1218-1263. McGraw-Hill, New York.

von Figura, K., Lögering, M., Mersmann, G., and Kresse, H. (1973). Sanfilippo B disease: serum assays for detection of homozygous and heterozygous individuals in three families. J. Pediat., 83, 607-611.

Fratantoni, J. C., Hall, C. W., and Neufeld, E. F. (1968a). The defect in Hurler's and Hunter's syndromes: faulty degradation of mucopolysaccharide. Proc. nat. Acad. Sci. (Wash.), 60, 699-706.

Fratantoni, J. C., Hall, C. W., and Neufeld, E. F. (1968b). Hurler and Hunter syndromes: mutual correction of the defect in cultured fibroblasts. Science, 162, 570-572.

Goldberg, J. M. (1973). Personal communication.

Goldberg, J. M. and Cotlier, E (1972). Specific isolation and analysis of mucopolysaccharides (glycosaminoglycans) from human urine. Clin. chim. Acta, 41, 19-27.

Hardingham, T. E. and Phelps, C. F. (1970). The glycosaminoglycans of neonatal rat skin. Biochem. J., 117, 813818.

Hata, R. and Nagai, Y. (1972). A rapid and micro method for separation of acidic glycosaminoglycans by two-dimensional electrophoresis. Analyt. Biochem., 45, 462-468.

Humbel, R. and Chamoles, N. A. (1972). Sequential thin layer chromatography of urinary acid glycosaminoglycans. Clin. chim. Acta, 40, 290-293.

Jeanloz, R. W. (1960). The nomenclature of mucopolysaccharides. Arthr. and Rheum., 3, 233-237.

Jenkins, P., Davies, G. R., and Harper, P. S. (1973). MorquioBrailsford disease. A report of four affected sisters with absence of excessive keratan sulphate in the urine. Brit. $J$. Radiol., 46, 668-675.

Kaplan, D. (1969). Classification of the mucopolysaccharidoses based on the pattern of mucopolysacchariduria. Amer. J. Med., 47, 721-729.

Kaplan, D., McKusick, V. A., Trebach, S., and Lazarus, R. (1968). Keratosulfate-chondroitin sulfate peptide from 
normal urine and from urine of patients with Morquio syndrome. (mucopolysaccharidosis IV). J. Lab. clin. Med., 71, 48-55.

Kresse, H. (1973). Mucopolysaccharidosis IIIA (Sanfilippo A disease): deficiency of a heparin sulfamidase in skin fibroblasts and leucocytes. Biochem. biophys. Res. Commun., 54, 1111-1118.

Lagunoff, D., Pritzl, P., and Scott, C. R. (1967). Urinary Nsulfate glycosaminoglycan excretion in children. Normal and abnormal values. Proc. Soc. exp. Biol. (N.Y.), 126, 34-38.

Lewis, P. W., Raine, D. N., and Kennedy, J. F. (1974). Recognition of the mucopolysaccharidoses by four screening tests, including a refinement of the albumin turbidity test, and their differentiation by electrophoretic separation of urinary glycosaminoglycans. Ann. clin. Biochem., 11, 67. 71.

Linker, A., Evans, L. R., and Langer, L. O. (1970). Morquio's disease and mucopolysaccharide excretion. J. Pediat., 77, 1039-1047.

Lippiello, L. and Mankin, H. J. (1971). Thin-layer chromatographic separation of the isomeric chondroitin sulfates, dermatan sulfate, and keratan sulfate. Analyt. Biochem., 39, 54-58.

McKusick, V. A. (1969). The nosology of the mucopolysaccharidoses. Amer. J. Med., 47, 730-747.

McKusick, V. A. (1972). Heritable Disorders of Connective Tissue, Chap. 11, pp. 521-686. C. V. Mosby, St. Louis.

McKusick, V. A., Kaplan, D., Wise, D., Hanley, W. B., Suddarth, S. B., Sevick, M. E., and Maumanee, A. E. (1965). The genetic mucopolysaccharidoses. Medicine (Baltimore), 44, 445-483.

Manley, G. and Hawksworth, J. (1966). Diagnosis of Hurler's syndrome in the hospital laboratory and the determination of its genetic type. Arch. Dis. Childh., 41, 9196.

Manley, G., Severn, M., and Hawksworth, J. (1968). Excretion patterns of glycosaminoglycans and glycoproteins in normal human urine. J. clin. Path., 21, 339-345.

Maroteaux, P. (1970). Différenciation biochemique des maladies de Hurler et de Hunter par fractionnement de l'héparitine sulfate. Rev. Europ. etud. clin. Biol., 15, 203205.

Maroteaux, P. and Lamy, M. (1967). Studying the mucopolysaccharidoses. Lancet, 2, 510.

Matalon, R., Arbogast, B., Justice, P., Brandt, I. K., and Dorfman, A. (1974). Morquio's syndrome: deficiency of a chondroitin sulfate $\mathrm{N}$-acetylhexosamine sulfate sulfatase. Biochem. biophys. Res. Commun., 61, 759-765.

Matalon, R. and Dorfman, A. (1972). Hurler's syndrome, and $a$-L-iduronidase deficiency. Biochem. biophys. Res. Commun., 47, 959-964.

Meyer, K., Grumbach, M. M., Linker, A., and Hoffman, P. (1958). Excretion of sulfated mucopolysaccharides in gargoylism (Hurler's syndrome). Proc. Soc. exp. Biol. (N.Y.), 97, 275-279.

Muir, H. (1969). The structure and metabolism of mucopolysaccharides (glycosaminoglycans) and the problem of the mucopolysaccharidoses. Amer. J. Med., 47, 673-690.

Murphy, D., Pennock, C. A., and London, K. J. (1974). Gas-liquid chromatographic measurement of glucosamine and galactosamine content of urinary glycosaminoglycans. Clin. chim. Acta, 53, 145-152.

O'Brien, J. S. (1972). Sanfilippo syndrome: profound deficiency of alpha-acetylglucosaminidase activity in organs and skin fibroblasts from type-B patients. Proc. nat. Acad. Sci. (Wash.), 69, 1720-1722.

Pedrini, V., Lenuzzi, L., and Zambotti, V. (1962). Isolation and identification of keratosulphate in urine of patients affected by Morquio-Ullrich disease. Proc. Soc. exp. Biol.,
$110,847-849$

Pennock, C. A., (1969). A modified screening test for glyç्ठ․ saminoglycan excretion. J. clin. Path., 22, 379.

Pennock, C. A. (1973). Glycosaminoglycan excretion. M Thesis, University of Bristol.

Pennock, C. A. Charles, R. G., and Stansbie, D. (197\%) Glycosaminoglycan fractions in normal human urirs Ann. clin. Biochem., 12, 207-211.

Pennock, C. A., Mott, M. G., and Batstone, G. F. (197界 Screening for mucopolysaccharidoses. Clin. chim. Acta, 28. 93-97.

Pennock, C. A., Wharton, B. A., and White, F. (197א? Urinary glycosaminoglycan excretion in the neonat period. Acta paediat. scand., 60, 299-300.

Pennock, C. A., White, F., Murphy, D., Charles, R. G., a $\overrightarrow{d \vec{d}}$ Kerr, H. (1973). Excess glycosaminoglycan excretion infancy and childhood. Acta paediat. scand., 62, 481-49क.

Pennock, C. A., White, F., and Wharton, B. A. (1972). CP. precipitable uronic acid: creatinine ratio in random urias samples collected from normal children. Acta paediano scand., 61, 125-127.

Procopsis, P. G., Turner, B., Ruxton, J. T., and Brown, D. (1968). Screening tests for mucopolysaccharidoses. ment. Defic. Res., 12, 13-17.

Renuart, A. W. (1966). Screening for inborn errors of metabolism associated with mental deficiency or neurg logical disorders or both. New Engl. J. Med., 274, 384-38黑

Robertson, W. V. and Harvey, J. (1972). The determinatiom of galactose in urinary acidic glycosaminoglycans as measure of keratan sulphate-like substances in urine Biochem. Med., 6, 246-256.

Robins, M. M., Stevens, H. F., and Linker, A. (19.63 Morquio's disease: an abnormality of mucopolysacchawide metabolism. J. Pediat., 62, 881-889.

Rosenfeld, L. (1971). Quantitative levels of the constitusin of acid mucopolysaccharides and other carbohydrace polymers in dialyzed normal human urine. Clin. chimo Acta, 31, 263-269.

Scott, J. E. (1960). Aliphatic ammonium salts in the assay acidic polysaccharides from tissues. Meth. bioche Anal., 8, 145-197.

Segni, G., Romano, C., and Tortorolo, G. (1964). Diagnost test for gargoylism. (Letter). Lancet, 2, 420.

Sjöberg, I., Franssön, L., Matalon, R., and Dorfman, (1973). Hunter's syndrome: a deficiency of L-idurono sulfate sulfatase. Biochem. biophys. Res. Commun., 548 1125-1132.

Sly, W. S., Quinton, B. A., McAlister, W. H., and Rimoin D. L. (1973). Beta glucuronidase deficiency: report of clinical, radiologic, and biochemical features of a ne mucopolysaccharidosis. J. Pediat., 82, 249-257.

Spranger, J. W. (1970). Biochemical definition of the mucos polysaccharidoses. $Z$. Kinderheilk, 108, 17-31.

Steiness, I. B. (1961). Acid mucopolysaccharides in urine is gargoylism. Pediatrics, 27, 112-117.

Stumpf, D. A., Austin, J. H., Crocker, A. C., and LaFrance M. (1973). Mucopolysaccharidosis Type VI (Maroteaux Lamy syndrome) I. Sulfatase B deficiency in tissues. Amenv J. Dis. Child., 126, 747-755.

Teller, W. M., Burke, E. C., Rosevear, J. W., and McKenziew B. F. (1962). Urinary excretion of acid mucopolysaco charides in normal children and patients with gargoylism J. Lab. clin. Med., 59, 95-101.

Teller, W. M. and Ziemann, A. (1969). Thin layer chromato graphy of urinary acid glycosaminoglycans, a screening? procedure for mucopolysaccharidoses. Hormone metab.0 Res., 1, 32-35.

Thompson, G. R. and Castor, C. W. (1966). The excretion o雨 nondialyzable urinary mucopolysaccharide in rheumatie and other systemic disease states. J. Lab. clin. Med., 68 
617-627.

Valdivieso, F., Martinez-Valverde, A., Maties, M., and Ugarte, M. (1973). Early diagnosis of hypermucopolysacchariduria. Clin. chim. Acta, 44, 357-360.

Van Hoof, F. and Hers, H. G. (1964). L'ultrastructure des cellules hépatiques dans la maladie de Hurler (gargoylisme). C. R. Acad. Sci. (Paris), 259, 1281-1283.

Wessler, E. (1967). Determination of acidic glycosaminoglycans (mucopolysaccharides) in urine by an ion exchange method. Application to "collagenoses", gargoylism, NailPatella Syndrome and Farber's disease. Clin. chim. Acta, 16, 235-243.

Wessler, E. (1968). Analytical and preparative separation of acidic glycosaminoglycans by electrophoresis in barium acetate. Analyt. Biochem, 26, 439-444.

Whiteman, P. (1973a). The quantitative measurement of alcian blue-glycosaminoglycan complexes. Biochem. J., 131, 343-350.

Whiteman, P. (1973b). The quantitative determination of glycosaminoglycans in urine with alcian blue $8 \mathrm{GX}$. Biochem. J., 131, 351-357.

Wiesmann, U. and Neufeld, E. F. (1970). Scheie and Hurler syndromes: apparent identity of the biochemical defect. Science, 169, 72-74.

Wusteman, F. S., Lloyd, A. G., and Dodgson, K. S. (1966) Thin-layer chromatography and the rapid identification of common acidic glycosaminoglycans. J. Chromatog., 21, 32-39. 